\title{
Polymorphisms of the Niemann-Pick C1-like 1 gene in a Japanese population
}

\author{
RIE OSAKI $^{1}$, HIROTSUGU IMAEDA ${ }^{1}$, KENICHIRO TAKAHASHI ${ }^{3}$, TAKEHIDE FUJIMOTO ${ }^{3}$, \\ TAKAYUKI TAKEUCHI ${ }^{2}$, YOSHIHIDE FUJIYAMA ${ }^{1}$ and AKIRA ANDOH $^{3}$ \\ ${ }^{1}$ Department of Medicine, Shiga University of Medical Science, Seta Tukinowa, Otsu; ${ }^{2}$ Department of Medicine, \\ Notogawa Hospital, Higashioumi; ${ }^{3}$ Division of Mucosal Immunology, Graduate School, \\ Shiga University of Medical Science, Seta Tukinowa, Otsu, Japan
}

Received September 13, 2012; Accepted October 11, 2012

DOI: $10.3892 /$ br.2012.24

\begin{abstract}
The Niemann-Pick C1 like 1 (NPC1L1) protein is a polytopic transmembrane protein responsible for dietary cholesterol absorption. Genetic variation in the NPCILl gene affects cholesterol absorption and serum cholesterol levels. However, NCP1L1 genotypes have not previously been invesigated. In this study, genotyping of the NPC1L1 gene was examined in healthy individuals as well as patients with hepatitis $\mathrm{C}$ virus (HCV) and inflammatory bowel disease (IBD). A total of 541 individuals were enrolled in the study, including 80 patients with HCV hepatitis, 205 with ulcerative colitis (UC) and 127 with Crohn's disease (CD). Genotyping was performed using TaqMan ${ }^{\circledR}$ SNP assays. Minor allelic frequencies of the $17345 \mathrm{C}>\mathrm{G}(\mathrm{rs} 2072183)$ and $19031 \mathrm{G}>\mathrm{A}$ (rs4720470) SNPs were found to be 0.40 and 0.30 , respectively. No significant differences were detected in serum HCV levels in the $1735 \mathrm{C}>\mathrm{G}$ or $19031 \mathrm{G}>\mathrm{A}$ SNPs. The $1735 \mathrm{C}>\mathrm{G}$ SNPs were not associated with total cholesterol (TC) levels in the healthy controls and/or HCV patients. However, statistically significant associations between the $1735 \mathrm{GG}$ variant and TC levels were detected in CD patients, with $1735 \mathrm{GG}$ carriers having the highest TC levels compared to the $1735 \mathrm{CC}$ and $1735 \mathrm{CG}$ carriers $(\mathrm{P}=0.048)$. Similar trends were noted in UC patients, but did not reach statistical significance $(\mathrm{P}=0.19)$. The 19031G>A SNPs were not associated with TC levels in the healthy controls or patients. This study showed the allelic and genotypic distribution of $1735 \mathrm{C}>\mathrm{G}$ and $19031 \mathrm{G}>\mathrm{ASNPS}$ of the NPC1L1 gene in a large number of subjects. The NPC1L1 1735GG variant may therefore be favorable for CD accompanied with malnutrition.
\end{abstract}

Correspondence to: Professor Akira Andoh, Division of Mucosal Immunology, Graduate School, Shiga University of Medical Science, Seta Tsukinowa, Otsu 520-2192, Japan

E-mail: andoh@belle.shiga-med.ac.jp

Key words: cholesterol absorption, hepatitis $\mathrm{C}$ virus hepatitis, inflammatory bowel disease

\section{Introduction}

Well-balanced cholesterol homeostasis in the body is crucial for human health. Clinical and animal studies have established a direct correlation between plasma cholesterol levels and the risk of coronary artery disease, which is the leading cause of mortality in developed countries $(1,2)$. Cholesterol homeostasis in the body is maintained mainly by de novo synthesis, intestinal absorption and biliary and intestinal excretion. Cholesterol biosynthesis is a well-defined energy-consuming and feedback-regulated process, which is mediated by a family of membrane-bound transcription factors and sterol regulatory element-binding proteins $(3,4)$.

The molecular mechanisms and regulation of intestinal cholesterol absorption were poorly understood until the discovery of the Niemann-Pick C1-like 1 (NPC1L1) protein (5). NPC1L1 is a polytopic transmembrane protein located on the brush border membrane of the small intestine in mammals and on the canalicular membrane of hepatocytes in primates $(6,7)$. It is essential for dietary cholesterol absorption and biliary cholesterol reabsorption. NPC1L1 recycles between the plasma membrane and the endocytic recycling compartment. Cholesterol depletion induces the transport of NPC1L1 towards the plasma membrane and cholesterol replenishment, generating the endocytosis of NPC1L1. In this way, NPC1L1 mediates cholesterol uptake through vesicular endocytosis. A growing body of data supports involvement of NPC1L1 and NPC1L1-dependent intestinal cholesterol absorption in metabolic diseases, such as non-alcoholic fatty liver disease, insulin resistance, diabetes and obesity, in addition to atherosclerotic coronary heart disease.

NPC1L1 is the molecular target of ezetimibe, an inhibitor of cholesterol absorption that has been approved for the treatment of hypercholesterolemia $(8,9)$. Ezetimibe binding to NPC1L1 may result in NPC1L1 protein conformational changes, thereby disturbing the interactions between NPC1L1 and free cholesterol, and ultimately inhibiting cholesterol-induced NPC1L1 endocytosis $(6,9,10)$. NPC1L1 has been reported as a hepatitis $\mathrm{C}$ virus (HCV) entry factor into hepatocytes amenable to therapeutic intervention (11). NPC1L1 expression is necessary for $\mathrm{HCV}$ infection, while ezetimibe potently blocks $\mathrm{HCV}$ uptake in vitro via a virion cholesterol-dependent step before 
Table I. Patient baseline characteristics.

\begin{tabular}{lcccccc}
\hline Characteristics & $\begin{array}{c}\text { Healthy } \\
\text { control }\end{array}$ & $\begin{array}{c}\text { HCV } \\
\text { hepatitis }\end{array}$ & $\begin{array}{c}\text { Ulcerative } \\
\text { colitis }\end{array}$ & $\begin{array}{c}\text { Crohn's } \\
\text { disease }\end{array}$ & Others & Total \\
\hline Number & 111 & 80 & 205 & 127 & 18 & 541 \\
Gender (male/female) & $53 / 58$ & $40 / 40$ & $117 / 88$ & $85 / 42$ & $7 / 11$ & $302 / 239$ \\
Age (years) & $58.6 \pm 10.6$ & $63.9 \pm 11.1$ & $42.8 \pm 14.5$ & $35.6 \pm 11.3$ & $53.4 \pm 15.5$ & $47.8 \pm 17.2$ \\
(range) & $(18-87)$ & $(34-80)$ & $(18-82)$ & $(16-69)$ & $(30-78)$ & $(16-87)$ \\
Body mass index $\left(\mathrm{kg} / \mathrm{m}^{2}\right)$ & $23.8 \pm 4.9$ & $23.4 \pm 3.8$ & $21.3 \pm 3.8$ & $20.4 \pm 3.1$ & $24.5 \pm 4.2$ & $22.0 \pm 4.1$ \\
(range) & $(14.7-47.6)$ & $(15.9-37.9)$ & $(13.5-40.8)$ & $(14.6-31.7)$ & $(19.6-35.4)$ & $(13.6-47.6)$ \\
\hline
\end{tabular}

Data are expressed as the mean $\pm \mathrm{SD}$ (range). $\mathrm{HCV}$, hepatitis $\mathrm{C}$ virus.

virion-cell membrane fusion (11). Moreover, ezetimibe inhibits infection by all major HCV genotypes and delays the establishment of HCV infection. Thus, NPC1L1 is thought to be a new antiviral target and potential therapeutic agent.

Significant inter-individual variability has been reported for the rates of intestinal cholesterol absorption and cholesterol reduction post-ezetimibe treatment. Genetic variation in NPC1L1 is considered to be one of the factors affecting serum cholesterol levels and the clinical response to ezetimibe $(12,13)$. However, NPC1L1 genotypes in the Japanese population have not been previously investigated. In this study, we performed genotyping of the NPC1L1 gene in a Japanese population, including apparently healthy individuals, HCV hepatitis and inflammatory bowel disease (IBD) patients.

\section{Patients and methods}

Study populations. A total of 541 individuals, who were treated at the Hospital of the Shiga University of Medical Science (Otsu, Japan) and the Notogawa Hospital (Higashioumi, Japan), were enrolled in the study. These individuals included 80 patients with $\mathrm{HCV}$ hepatitis, 205 with ulcerative colitis (UC) and 127 with Crohn's disease (CD). Table I shows the patient demographic characteristics. Informed consent was obtained from the patients. The ethics committee of each participating medical center approved this study.

Genotyping. Samples were genotyped using TaqMan ${ }^{\circledR}$ SNP assays (Applied Biosystems, Inc., Foster City, CA, USA), as previously described (14). Six single nucleotide polymorphisms (SNPs) in the NPC1L1 locus were genotyped in this study: four SNPs in the protein-coding region [39C >A (rs41279633), $1759 \mathrm{G}>\mathrm{A}(\mathrm{rs} 61737028), 1735 \mathrm{C}>\mathrm{G}(\mathrm{rs} 2072183)$ and $25216 \mathrm{G}>\mathrm{A}$ (rs52815063)] and two SNPs in the non-coding region [19031G>A (rs4720470) and 10848A>G (rs11763759)]. HCV RNA levels were analyzed using the TaqMan RT-PCR test. The measurement ranges of these assays were 1.2-7.8 log IU.

Statistical analysis. Hardy-Weinberg equilibrium analysis was performed in these subjects by comparing the detected distribution of the allelic frequencies with the theoretical distribution estimated from the SNP allelic frequencies. P>0.05 (Chi-square statistics) was considered to indicate equilibrium. The categorical variables were presented as frequencies and percentages as needed. The continuous variables were reported as the means $\pm \mathrm{SD}$ (range). The Kruskal-Wallis H test was used for the statistical analyses. $\mathrm{P}<0.05$ was considered to indicate a statistically significant difference.

\section{Results}

Patient characteristics and genotyping. The participating patients had a mean age of $47.8 \pm 17.2$ years and a mean body mass index of $22.0 \pm 4.1 \mathrm{~kg} / \mathrm{m}^{2}$ (Table I). Six polymorphisms of the NPC1L1 gene, represented in the National Center for Biotechnology Information SNP database, were investigated. The genotype distributions and allelic frequencies are listed in Table II. The allelic frequencies conformed to the Hardy-Weinberg equilibrium ( $\mathrm{P}>0.05)$. Four SNPs [39C $>\mathrm{A}$ (rs41279633), 1759G $>$ A (rs61737028), 25216T $>$ A (rs52815063) and $10848 \mathrm{~A}>\mathrm{G}$ (rs11763759)] showed a skewed distribution, and the minor allelic frequencies were extremely low in the Japanese population. Therefore, we focused on two SNPs [1735C > G (rs2072183) and 19031G>A (rs4720470)] in the following analyses of the correlation between genotypes and clinical parameters. Our findings indicated that the minor allelic frequencies of the $17345 \mathrm{C}>\mathrm{G}$ and $19031 \mathrm{G}>\mathrm{A}$ SNPs in the Japanese population were 0.40 and 0.30 , respectively.

Effects of NPC1L1 of minor alleles. Recent studies have demonstrated that NPC1L1 mediates HCV entry into hepatocytes, and ezetimibe blocks this response in vivo $(11,15)$. Based on these reports, we checked for differences in the serum HCV RNA levels of the $1735 \mathrm{C}>\mathrm{G}$ and $19031 \mathrm{G}>\mathrm{A}$ SNPs (Tables III and IV). However, no significant differences were detected in serum HCV levels in the $1735 \mathrm{C}>\mathrm{G}$ or $19031 \mathrm{G}>\mathrm{A}$ SNPs, and this result indirectly suggests that the $1735 \mathrm{C}>\mathrm{G}$ or $19031 \mathrm{G}>\mathrm{A}$ SNPs may not affect the HCV entry into hepatocytes in the Japanese population.

Total cholesterol and total triglyceride levels stratified by the $1735 \mathrm{C}>\mathrm{G}$ SNPs and diseases are shown in Table III. The $1735 \mathrm{C}>\mathrm{G}$ SNPs were not associated with total cholesterol and triglyceride levels in the healthy controls and $\mathrm{HCV}$ patients. However, homozygotes of the minor alleles (1735GG variant) were associated with higher total cholesterol levels in the IBD patients, including UC and CD. Statistically significant associations between the $1735 \mathrm{GG}$ variant and total cholesterol levels were most pronounced in CD, with the $1735 \mathrm{GG}$ carriers 
Table II. Frequency of NPC1L1 polymorphisms.

\begin{tabular}{|c|c|c|c|c|c|c|}
\hline dbSNP number & Nucleotide & Location & Major homo & $\begin{array}{c}\text { Major/minor } \\
\text { hetero }\end{array}$ & Minor homo & Allele frequency \\
\hline rs41279633 & $39 \mathrm{C}>\mathrm{A}$ & Exon 1 & 0.987 & 0.013 & 0.0 & A: 0.007 \\
\hline rs2072183 & $1735 \mathrm{C}>\mathrm{G}$ & Exon 2 & 0.380 & 0.437 & 0.183 & G: 0.40 \\
\hline rs61737028 & $1759 \mathrm{G}>\mathrm{A}$ & Exon 2 & 0.996 & 0.002 & 0.002 & A: 0.004 \\
\hline rs52815063 & 25216T/A & Exon 17 & 1.00 & 0 & 0 & A: 0.0 \\
\hline rs4720470 & $19031 \mathrm{G}>\mathrm{A}$ & Intron 10 & 0.502 & 0.40 & 0.098 & A: 0.30 \\
\hline rs11763759 & $10848 \mathrm{~A}>\mathrm{G}$ & Intron 10 & 0.955 & 0.043 & 0.002 & $\mathrm{G}: 0.05$ \\
\hline
\end{tabular}

$\mathrm{dbSNP}$ and nucleotide were derived from National Center for Biotechnology single-nucleotide polymorphism database. NPC1L1, Niemann-Pick C1-like 1; homo, homozygotes; hetero, heterozygotes.

Table III. Effects of the NPC1L1 (rs2072183; 1735C>G) minor allele on clinical parameters.

\begin{tabular}{|c|c|c|c|c|}
\hline Clinical parameters & $1735 \mathrm{C} / \mathrm{C}$ & $1735 \mathrm{C} / \mathrm{G}$ & $1735 \mathrm{G} / \mathrm{G}$ & P-value \\
\hline $\begin{array}{l}\text { HCV RNA levels of HCV hepatitis } \\
\text { patients }(n=69)(\log 10 \mathrm{IU} / \mathrm{ml})\end{array}$ & $6.1 \pm 1.5(1.2-7.7)$ & $6.3 \pm 1.6(1.2-7.2)$ & $6.3 \pm 1.0(4.2-7.4)$ & 0.36 \\
\hline \multicolumn{5}{|l|}{ Total cholesterol (mg/dl) } \\
\hline of total subjects $(n=439)$ & $176 \pm 33.4(98.4-303)$ & $179 \pm 38.9(70-300)$ & $176.5 \pm 43.1(77-287)$ & 0.51 \\
\hline of healthy control $(n=88)$ & $197 \pm 36.7(105-256)$ & $191 \pm 33.7(108-266)$ & $186 \pm 48.7(125-287)$ & 0.93 \\
\hline of HCV hepatitis $(n=69)$ & $158.5 \pm 34.7(100-252)$ & $164 \pm 31.7(103-245)$ & $164 \pm 31.7(103-245)$ & 0.83 \\
\hline $\begin{array}{l}\text { of healthy control and HCV } \\
\text { patients }(n=157)\end{array}$ & $179 \pm 38.6(100-256)$ & $182.8 \pm 34.7(103-206)$ & $177.7 \pm 46.9(117-287)$ & 0.92 \\
\hline of IBD patients $(n=266)$ & $174.5 \pm 40.2(98.4-303)$ & $173 \pm 41.4(70-300)$ & $179.5 \pm 38.3(104-285)$ & 0.26 \\
\hline of ulcerative colitis $(n=164)$ & $194.5 \pm 33.5(70-300)$ & $194 \pm 38.2(70-300)$ & $196 \pm 32.8(143-263)$ & 0.19 \\
\hline of Crohn's disease $(n=102)$ & $147 \pm 36.9(73-285)$ & $141 \pm 34.1(85-236)$ & $157 \pm 40.8(104-285)$ & $0.048^{\mathrm{a}}$ \\
\hline \multicolumn{5}{|l|}{ Total triglyceride (mg/dl) } \\
\hline of total subjects $(n=439)$ & $98 \pm 77.9(16-565)$ & $98.5 \pm 74.6(30-610)$ & $104.5 \pm 60.2(18-344)$ & 0.78 \\
\hline of healthy control $(n=88)$ & $92 \pm 56.1(16-236)$ & $108 \pm 80.3(34-362)$ & $122 \pm 69.3(53-344)$ & 0.41 \\
\hline of HCV hepatitis $(n=69)$ & $87 \pm 63.5(34-278)$ & $91 \pm 96.2(30-610)$ & $91 \pm 72.9(41-275)$ & 0.78 \\
\hline $\begin{array}{l}\text { of healthy control and HCV } \\
\text { patients }(n=157)\end{array}$ & $89 \pm 58.9(16-278)$ & $103 \pm 87.7(30-610)$ & $119 \pm 69.3(41-344)$ & 0.28 \\
\hline of IBD patients $(n=266)$ & $102 \pm 68.7(34-435)$ & $95.5 \pm 61.2(35-317)$ & $100 \pm 53.5(30-253)$ & 0.72 \\
\hline of ulcerative colitis $(n=164)$ & $100 \pm 62.0(35-317)$ & $98 \pm 70.3(35-317)$ & $104 \pm 52.7(42-251)$ & 0.57 \\
\hline of Crohn's disease $(n=102)$ & $93 \pm 52.8(30-288)$ & $93 \pm 50.3(35-288)$ & $80 \pm 59.5(30-253)$ & 0.094 \\
\hline \multicolumn{5}{|l|}{ Body mass index $\left(\mathrm{kg} / \mathrm{m}^{2}\right)$} \\
\hline of healthy control $(n=88)$ & $22.6 \pm 4.4(15.8-34.6)$ & $24.5 \pm 5.5(18.0-47.6)$ & $21.6 \pm 4.1(14.7-30.7)$ & 0.21 \\
\hline $\begin{array}{l}\text { of healthy control and HCV } \\
\text { hepatitis }(n=157)\end{array}$ & $22.6 \pm 3.9(15.8-34.6)$ & $24.6 \pm 5.0(15.9-47.6)$ & $21.6 \pm 3.8(14.7-30.7)$ & n.d. \\
\hline
\end{tabular}

${ }^{a} \mathrm{P}<0.05$ was considered to be statistically significant. Data are expressed as the mean \pm SD. NPC1L1, Niemann-Pick C1-like $1 ;$ HCV, hepatitis $\mathrm{C}$ virus; n.d., no data.

having the highest total cholesterol levels as compared to the $1735 \mathrm{CC}$ and $1735 \mathrm{CG}$ carriers $(\mathrm{P}=0.048)$. Similar trends were noted in the UC patients, but did not reach statistical significance $(\mathrm{P}=0.19$ for total cholesterol). By contrast, the total triglyceride levels of the $\mathrm{CD}$ patients tended to be lower in the $1735 \mathrm{GG}$ carriers as compared to the $1735 \mathrm{CC}$ and $1735 \mathrm{CG}$ carriers $(\mathrm{P}=0.094)$.
Baseline total cholesterol and total triglyceride levels stratified by the $19031 \mathrm{G}>\mathrm{A}$ SNPs and diseases are shown in Table IV. The 19031G>A SNPs were not associated with total cholesterol levels in the healthy controls or HCV/IBD patients. However, homozygotes of the minor alleles (19031AA) were associated with higher triglyceride levels in the IBD patients. Significant associations between the 19031AA variant and 
Table IV. Effects of the NPC1L1 (rs4720470; 19031G>A) minor allele on clinical parameters.

\begin{tabular}{|c|c|c|c|c|}
\hline Clinical parameters & $19031 \mathrm{G} / \mathrm{G}$ & 19031G/A & 19031A/A & P-value \\
\hline $\begin{array}{l}\text { HCV RNA levels of HCV hepatitis } \\
\text { patients }(\mathrm{n}=72)(\log 10 \mathrm{IU} / \mathrm{ml})\end{array}$ & $6.1 \pm 1.5(1.2-7.7)$ & $6.3 \pm 1.7(1.2-7.4)$ & $6.1 \pm 1.1(3.7-7.2)$ & 0.75 \\
\hline \multicolumn{5}{|l|}{ Total cholesterol (mg/dl) } \\
\hline of total subjects $(\mathrm{n}=486)$ & $176 \pm 41.1(70-303)$ & $178.4 \pm 38.9(98-285)$ & $176 \pm 44.3(98-266)$ & 0.78 \\
\hline of healthy control $(n=101)$ & $198.5 \pm 39.5(108-287)$ & $187 \pm 33.2(124-267)$ & $200 \pm 51.4(105-266)$ & 0.88 \\
\hline of HCV hepatitis $(n=72)$ & $161 \pm 33.8(106-252)$ & $172.5 \pm 33.8(100-231)$ & $154.5 \pm 29.3(103-211)$ & 0.27 \\
\hline $\begin{array}{l}\text { of healthy control and HCV } \\
\text { patients }(n=173)\end{array}$ & $179.5 \pm 39.8(106-287)$ & $184 \pm 34.5(100-267)$ & $161 \pm 47.1(103-266)$ & 0.66 \\
\hline of IBD patients $(n=298)$ & $174.5 \pm 39.7(96-285)$ & $174 \pm 38.7(103-285)$ & $185.8 \pm 43.7(98-265)$ & 0.85 \\
\hline of ulcerative colitis $(n=185)$ & $188 \pm 38.2(70-303)$ & $191 \pm 32.5(121-285)$ & $193.5 \pm 34.4(105-264)$ & 0.76 \\
\hline of Crohn's disease $(n=113)$ & $156 \pm 39.0(73-285)$ & $150 \pm 35.8(103-262$ & $136.5 \pm 46.8(98-265)$ & 0.41 \\
\hline \multicolumn{5}{|l|}{ Total triglyceride (mg/dl) } \\
\hline of total subjects $(n=541)$ & $94.5 \pm 72.7(18-565)$ & $102.5 \pm 73.8(16-610)$ & $109 \pm 73.8(35-348)$ & 0.069 \\
\hline of healthy control $(n=101)$ & $108 \pm 73.6(34-344)$ & $119 \pm 59.2(16-362)$ & $119.5 \pm 87.3(62-295)$ & 0.63 \\
\hline of HCV hepatitis $(n=72)$ & $87 \pm 65.7(40-308)$ & $98 \pm 103.7(30-610)$ & $89 \pm 57.5(58-232)$ & 0.57 \\
\hline $\begin{array}{l}\text { of healthy control and HCV } \\
\text { patients }(n=173)\end{array}$ & $92 \pm 70.6(34-344)$ & $112 \pm 79.9(16-610)$ & $99 \pm 77.7(58-205)$ & 0.51 \\
\hline of IBD patients $(n=298)$ & $102 \pm 68.7(34-435)$ & $100 \pm 71.5(34-435)$ & $113 \pm 57.3(35-281)$ & 0.23 \\
\hline of ulcerative colitis $(n=185)$ & $99.5 \pm 72.1(34-565)$ & $96 \pm 73.3(34-405)$ & $108 \pm 57.9(51-281)$ & 0.70 \\
\hline of Crohn's disease $(n=111)$ & $85.5 \pm 74.0(30-426)$ & $111 \pm 69.0(42-435)$ & $117.5 \pm 58.5(35-223)$ & $0.050^{\mathrm{a}}$ \\
\hline \multicolumn{5}{|l|}{ Body mass index $\left(\mathrm{kg} / \mathrm{m}^{2}\right)$} \\
\hline of healthy control $(n=111)$ & $23.9 \pm 5.3(16.2-47.6)$ & $25.7 \pm 4.3(18.3-32.7)$ & $25.7 \pm 4.3(18.3-32.7)$ & 0.27 \\
\hline $\begin{array}{l}\text { of healthy control and HCV } \\
\text { hepatitis }(n=173)\end{array}$ & $23.5 \pm 4.9(16.2-47.6)$ & $23.1 \pm 4.0(14.7-36.0)$ & $24.6 \pm 3.8(18.3-32.7)$ & 0.44 \\
\hline
\end{tabular}

Data are expressed as the mean $\pm \mathrm{SD}$. ${ }^{\mathrm{P}}<0.05$ was considered to be statistically significant. HCV, hepatitis $\mathrm{C}$ virus; NPC1L1, Niemann-Pick C1-like 1.

triglyceride levels were most pronounced in $\mathrm{CD}$, with the 19031AA carriers having the highest triglyceride levels as compared to the 19031GG and 19031GA carriers $(\mathrm{P}=0.050)$. Similar trends were also observed in the UC patients, but did not reach statistical significance $(\mathrm{P}=0.70)$.

\section{Discussion}

Multiple rare sequence variants in the NPC1L1 gene have recently been found to be associated with variations in cholesterol absorption and plasma cholesterol levels $(12,13,16,17)$. In their study, Cohen et al (18) identified a series of non-synonymous sequence variations of NPC1L1 associated with high or low cholesterol absorption using the campesterol:lathosterol ratio as a surrogate marker of cholesterol absorption (18). Certain sequence variations associated with low cholesterol absorption destabilized NPC1L1, resulting in lower steady-state levels of NPC1L1 (19). Furthermore, genetic variation in NPC1L1 is now considered to be one of the factors that affect serum cholesterol levels and the clinical response to ezetimibe $(12,13)$. However, a systematic examination and comparison of these NPC1L1 variants remains incomplete.
The present study investigated the allelic and genotypic distribution of $1735 \mathrm{C}>\mathrm{G}(\mathrm{rs} 2072183)$ and $19031 \mathrm{G}>\mathrm{A}$ (rs4720470) SNPs in the NPC1L1 gene in a large number of Japanese subjects. The frequencies of the NPC1L1 1735G allele and 19031A allele were 40 and 30\%, respectively. The genotype distribution of $1735 \mathrm{C}>\mathrm{G}$ was identical to that of a previous report in a Japanese population by Maeda et al (20). By contrast, the minor allelic frequencies of the 4 SNPs [39C $>$ A (rs41279633), 1759G $>$ A (rs61737028), 25216T $>$ A (rs52815063) and 10848A $>\mathrm{G}$ (rs11763759)] were found to be extremely low in the Japanese population.

The frequency of the NPC1L1 $1735 \mathrm{G}$ minor allele was different in the Japanese population (40\%) and other ethnic communities. Hegele et al (21) reported that the frequency of the minor allele was $25.0 \%$ and the frequencies of the $\mathrm{CC}$ and GG genotypes were 55 and $5 \%$ in the Canadian population. Furthermore, Siomon et al (12) reported that the minor allelic frequency was 21.9, 28.3 and $17.9 \%$ in healthy Caucasians, African Americans and Hispanics, respectively. In Asian populations, Chen et al (22) analyzed the genetic polymorphisms of the NPC1L1 gene in a Chinese population and found that the frequency of the minor allele was $35.7 \%$ and the frequencies of the CC and GG genotypes were 39.3 and $10.7 \%$, respectively. 
These were lower compared to the results of the present study. In addition, the frequency of the NPC1L1 19031A minor allele in the Japanese population (30\%) was different from that in previous studies. Simon et al (12) reported that the frequency of 19031A was 4.9, 10.4 and 4.6\% in Caucasians, African American and Hispanics, respectively. These were lower compared to the results of the present study. Thus, these results suggest that the prevalence of the $1735 \mathrm{G}$ and/or 19031 A allele variants in the NPC1L1 gene may have an ethnic specificity.

Recent studies have demonstrated that NPC1L1 mediates HCV entry into hepatocytes $(11,15)$. However, there was no correlation between serum HCV levels and the $1735 \mathrm{C}>\mathrm{G}$ or $19031 \mathrm{G}>$ A SNPs. This indirectly suggests that the $1735 \mathrm{C}>\mathrm{G}$ or $19031 \mathrm{G}>\mathrm{A}$ SNPs have no involvement in HCV entry into hepatocytes in the Japanese population and further investigation is required in other SNP carriers in the future.

A recent meta-analysis of 46 participating studies demonstrated that a mutation of $1735 \mathrm{C}>\mathrm{G}$ (rs2072183) had an important correlation with serum TC and LDL-C levels (23). The minor allele $1735 \mathrm{G}$ has been reported to be associated with relatively higher TC and LDL-C levels in a European population, while $1735 \mathrm{GG}$ carriers showed higher LDL-C levels as compared to CC and CG carriers (17). In their study Maeda et al (20) demonstrated that the campesterol level, a marker of cholesterol absorption, was significantly higher in the GG vs. the CG/CC genotypes in a Japanese population. The minor allele $1735 \mathrm{G}$ is also associated with non-responsiveness to ezetimibe and this is possibly due to the higher absorption of cholesterol (13). By contrast, a negative correlation between the $1735 \mathrm{G}$ minor allele and serum TC levels has been shown in several previous reports. Simon et al (12) reported that there was no correlation between $1735 \mathrm{G}$ and basal cholesterol levels in healthy individuals, including Caucasians, African Americans and Hispanics. Similar results have also been reported by Zhao et al (24). In this study, no correlation was detected between $1735 \mathrm{C}>\mathrm{G}$ SNPs and TC levels, with the exception of CD. The $1735 \mathrm{GG}$ carriers with CD showed a significant elevation of their TC levels as compared to $\mathrm{CC}$ and CG carriers. CD is a chronic inflammatory disorder of the intestine, and is frequently accompanied by a malnutrition state (25). Accelerated cholesterol absorption due to the $1735 \mathrm{GG}$ variant might become apparent in such a malnourished condition, and is considered favorable for CD patients.

No significant correlations were detected between the NPC1L1 19031A minor allele and TC levels. The functional change in the NPC1L1 protein associated with the 19031A minor allele remains unclear. Wang et al (13) previously reported that the minor allelic frequencies of the $19031 \mathrm{G}>\mathrm{A}$ genotype were equally detected in responders and nonresponders to ezetimibe. This observation suggests that the 19031A minor allele may not be associated with functional changes in the NPC1L1 protein.

In conclusion, we analyzed the NPC1L1 $1735 \mathrm{C}>\mathrm{G}$ and 19031G >A polymorphisms, and demonstrated an association with serum lipid levels in a Japanese population. Furthermore, we investigated the association between the NPC1L1 1735C > G and/or 19031G >A polymorphisms with HCV RNA levels. The NPC1L1 1735GG variant may be associated with the active absorption of cholesterol, and may be favorable for CD accompanied by malnutrition.

\section{Acknowledgements}

This study was supported by MSD Co., Ltd (Tokyo, Japan).

\section{References}

1. Roger VL, Go AS, Lloyd-Jones DM, et al: Heart disease and stroke statistics - 2011 update: a report from the American Heart Association. Circulation 123: e18-e209, 2011.

2. Roger VL, Go AS, Lloyd-Jones DM, et al: Heart disease and stroke statistics - 2012 update: a report from the American Heart Association. Circulation 125: e2-e220, 2012.

3. Goldstein JL and Brown MS: Regulation of the mevalonate pathway. Nature 343: 425-430, 1990.

4. Wang LJ and Song BL: Niemann-Pick C1-Like 1 and cholesterol uptake. Biochim Biophys Acta 1821: 964-972, 2012.

5. Altmann SW, Davis HR Jr, Zhu LJ, et al: Niemann-Pick C1 Like 1 protein is critical for intestinal cholesterol absorption. Science 303: 1201-1204, 2004.

6. Betters JL and Yu L: NPC1L1 and cholesterol transport. FEBS Lett 584: 2740-2747, 2010.

7. Jia L, Betters JL and Yu L: Niemann-pick C1-like 1 (NPC1L1) protein in intestinal and hepatic cholesterol transport. Annu Rev Physiol 73: 239-259, 2011.

8. Suchy D, Labuzek K, Stadnicki A and Okopien B: Ezetimibe - a new approach in hypercholesterolemia management. Pharmacol Rep 63: 1335-1348, 2011.

9. Xie C, Zhou ZS, Li N, et al: Ezetimibe blocks the internalization of NPC1L1 and cholesterol in mouse small intestine. J Lipid Res: 2092-2101, 2012

10. Yu L, Bharadwaj S, Brown JM, et al: Cholesterol-regulated translocation of NPC1L1 to the cell surface facilitates free cholesterol uptake. J Biol Chem 281: 6616-6624, 2006.

11. Sainz B Jr, Barretto N, Martin DN, et al: Identification of the Niemann-Pick C1-like 1 cholesterol absorption receptor as a new hepatitis C virus entry factor. Nat Med 18: 281-285, 2012.

12. Simon JS, Karnoub MC, Devlin DJ, et al: Sequence variation in NPC1L1 and association with improved LDL-cholesterol lowering in response to ezetimibe treatment. Genomics 86: 648-656, 2005.

13. Wang J, Williams CM and Hegele RA: Compound heterozygosity for two non-synonymous polymorphisms in NPC1L1 in a non-responder to ezetimibe. Clin Genet 67: 175-177, 2005.

14. Livak KJ: Allelic discrimination using fluorogenic probes and the 5' nuclease assay. Genet Anal 14: 143-149, 1999.

15. Ray K: Hepatitis: NPC1L1 identified as a novel HCV entry factor. Nat Rev Gastroenterol Hepatol 9: 124, 2012.

16. Wang LJ, Wang J, Li N, Ge L, Li BL and Song BL: Molecular characterization of the NPC1L1 variants identified from cholesterol low absorbers. J Biol Chem 286: 7397-7408, 2011.

17. Polisecki E, Peter I, Simon JS, et al: Genetic variation at the NPC1L1 gene locus, plasma lipoproteins, and heart disease risk in the elderly. J Lipid Res 51: 1201-1207, 2010.

18. Cohen JC, Pertsemlidis A, Fahmi S, et al: Multiple rare variants in NPC1L1 associated with reduced sterol absorption and plasma low-density lipoprotein levels. Proc Natl Acad Sci USA 103: 1810-1815, 2006.

19. Fahmi S, Yang C, Esmail S, Hobbs HH and Cohen JC: Functional characterization of genetic variants in NPC1L1 supports the sequencing extremes strategy to identify complex trait genes. Hum Mol Genet 17: 2101-2107, 2008.

20. Maeda T, Honda A, Ishikawa T, et al: A SNP of NPC1L1 affects cholesterol absorption in Japanese. J Atheroscler Thromb 17: 356-360, 2010.

21. Hegele RA, Guy J, Ban MR and Wang J: NPC1L1 haplotype is associated with inter-individual variation in plasma low-density lipoprotein response to ezetimibe. Lipids Health Dis 4: 16, 2005.

22. Chen CW, Hwang JJ, Tsai CT, et al: The g.-762T $>$ C polymorphism of the NPC1L1 gene is common in Chinese and contributes to a higher promoter activity and higher serum cholesterol levels. J Hum Genet 54: 242-247, 2009.

23. Teslovich TM, Musunuru K, Smith AV, et al: Biological, clinical and population relevance of 95 loci for blood lipids. Nature 466: 707-713, 2010.

24. Zhao HL, Houweling AH, Vanstone CA, et al: Genetic variation in ABC G5/G8 and NPC1L1 impact cholesterol response to plant sterols in hypercholesterolemic men. Lipids 43: 1155-1164, 2008.

25. Lomer MC: Dietary and nutritional considerations for inflammatory bowel disease. Proc Nutr Soc 70: 329-335, 2011. 